\title{
Study of Capacitance Behavior of PANI/ $\mathrm{TiO}_{2} / \mathrm{GO}$
}

\author{
Ajay Kumar Sharma, Rajiv Kumar, Pawan Kumar Jain \\ Department of Physics, Swami Keshvanand Institute of Technology, Management and Gramothan, Jaipur- \\ 302017 (INDIA) \\ Email- ajaymnit19@gmail.com \\ Received 23.10.2020 received in revised form 24.10.2020, accepted 31.10.2020
}

\begin{abstract}
This manuscript present a synthesis of Polyaniline/ Titanium oxide/Grapheme oxide (PANI/ $\mathrm{TiO}_{2} / \mathrm{GO}$ ) nanocomposites using an insitu chemical oxidation polymerization of aniline in presence of colloidal graphene oxide (GO) nanoparticles and Ammonium peroxide sulfate (APS) use as an oxidant at $0-5^{\circ} \mathrm{C}$ in air. This paper deals with the systematic study of variation of capacitance with respect to frequency of pure Polyaniline (PANI), Polyaniline/ Titanium oxide $\left(\mathrm{PANI}^{\mathrm{TiO}} \mathrm{T}_{2}\right)$ and Polyaniline/ Titanium oxide/Grapheme oxide (PANI/TiO $/$ /GO) nanocomposites. Samples are structurally characterized through scanning electron microscopy (SEM) technique. The study shows that capacitance of pure PANI enhances slightly on dispersing $\mathrm{TiO}_{2}$ at 2 wt $\%$ and further doping of $\mathrm{GO}$ at $0.3 \mathrm{wt} \%$ improves capacitance for this sample.
\end{abstract}

Keywords: $\quad \mathrm{PANI} / \mathrm{TiO}_{2} / \mathrm{GO}$ nanocomposite, Oxidation polymerization, Capacitance, XRD and SEM.

\section{INTRODUCTION}

Among conducting polymers, Polyaniline (PANI) has unique characteristics like high thermal stability, excellent electrical properties and low cost makes it suitable for molecular electronics applications[1]-[3]. Its electrical conductivity can easily controlled by two methods (i) protonation and (ii) charge transfer doping method, that makes it a suitable material for designing microelectronic devices, actuators and sensors[4]-[6]. Due to superior dielectric constant, PANI can also be used in fabrication of integrated electronic circuits such as capacitor. Among various polymorphs, $\mathrm{TiO}_{2}$ has a wide energy bandgap (3.2eV) semiconductor material [7]-[9] potentially used in solar cells, catalysis, optoelectronic devices and dielectric ceramics in view of new kind of carbon materials graphene oxide (GO) has also received great attention by researchers [8], [10], [11]. Graphene oxide depicts moderate electrical conductivity, large specific surface area, low cost, excellent chemical and mechanical stability and it can be easily obtained from graphite by a various methods[12][14]. So, the supercapacitors electrode based on PANI/TiO ${ }_{2}$, PANI/CNT and PANI/GO nanocomposites have received much attention. In the present paper, we have discussed the structural and capacitive performance of $\mathrm{PANI}, \mathrm{PANI} / \mathrm{TiO}_{2}$ and $\mathrm{PANI} / \mathrm{TiO}_{2} / \mathrm{GO}$.

\section{EXPERIMENTAL DETAILS}

Recently reported that Pure PANI was synthesized by in-situ chemical oxidative polymerization technique at temperature range 0 $5^{0} \mathrm{C}[15][16]$. Graphene oxide (GO) is obtained by the Hummer's Method [17]. The PANI/TIO ${ }_{2}$ (at 2 wt $\% \mathrm{TiO}_{2}$ ) and $\mathrm{PANI} / \mathrm{TiO}_{2} / \mathrm{GO}$ (at $0.3 \mathrm{wt} \% \mathrm{GO}$ ) composites was prepared by an in-situ chemical oxidation polymerization of aniline in presence of colloidal $\mathrm{TiO}_{2}$ nanoparticles and light yellow suspension of GO respectively, using Ammonium peroxide sulfate (APS) as an oxidant at $0-5^{0} \mathrm{C}$ in air. The surface morphology of the samples is determined by Scanning Electron Microscopy (SEM) using quanta Fe 200 model. The capacitance of these composites is analyzed with impedance analyzer (Agilent 4294A precision).

\section{RESULTS AND DISCUSSION}

3.1 Scanning electron microscopy (SEM) Analysis

The surface morphology of Pure PANI, $\mathrm{PANI} / \mathrm{TiO}_{2}$ and $\mathrm{PANI} / \mathrm{TiO}_{2} / \mathrm{GO}$ nanocomposite is determined by SEM as shown in Fig. 1(a)-(c).

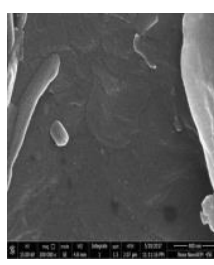

(a)

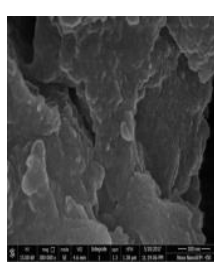

(b)

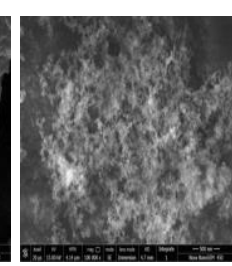

(c)
Figure 1: SEM micrographs of (a) Pure PANI (b) PANI/TiO 2 (2wt.\%), (c) PANI/ $\mathrm{TiO}_{2}(2 \mathrm{wt} . \%) / \mathrm{GO}(0.3 \mathrm{wt} . \%)$

Fig. 1 (a) and (b) shows the SEM image of pure PANI and $\mathrm{PANI} / \mathrm{TiO}_{2}$ nanoparticles. It shows that 
the dispersion of $\mathrm{TiO}_{2}$ nanocrystals influences the morphology of PANI greatly. The SEM micrograph of $\mathrm{PANI} / \mathrm{TiO}_{2}$ is not so much smooth and so many uneven lumps and holes are clearly visible. SEM micrograph fig.1(c) depicts that further doping of GO significantly affects the morphology of the resulting PANI/ $\mathrm{TiO}_{2} / \mathrm{GO}$ composites, which looks like formation of more compact structure.

\subsection{Frequency dependent capacitance profile}

Fig. 2 shows the dependence of capacitance as a function of frequency at room temperature for Pure PANI, PANI/ $\mathrm{TiO}_{2}$ and PANI/ $\mathrm{TiO}_{2} / \mathrm{GO}$ nanocomposites.

It was observed that at lower frequencies range the capacitance is high after that as frequency increase, capacitance decreases abruptly then it becomes nearly constants at very high frequencies, this indicate the usual dispersal. A very large value of capacitance at lower frequencies indicate the corresponding high value of dielectric constant as compared to the value at the higher frequency that can be ascribed to the presence of atomic, ionic, interfacial, dipolar and electronic contribution [18]. Dispersion of GO in PANI/ $\mathrm{TiO}_{2}$ causes formation of polaron and bipolarons to the polarization as a result dielectric properties and hence capacitance increases.

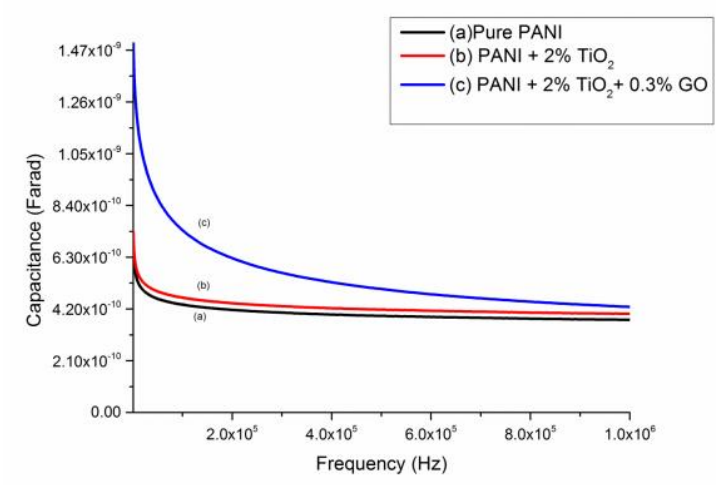

Figure 2: Capacitance Vs frequency of PANI and $\mathrm{PANI} \mathrm{TiO}_{2} / \mathrm{GO}$ nanocomposites

\section{CONCLUSION}

From the above, following conclusions can be drawn:

$>$ SEM micrographs reveal that structure become more compact in the presence of graphene oxide $(\mathrm{GO})$ in $\mathrm{PANI} / \mathrm{TiO}_{2}$ sample.

$>$ Dispersion of $\mathrm{TiO}_{2}$ in PANI matrix increases its capacitive property, which is further enhances on mixing of GO.

\section{REFERENCES}

[1] A. Kumar, V. Kumar, and K. Awasthi, "PolyanilineCarbon Nanotube Composites: Preparation Methods, Properties, and Applications," Polym. - Plast. Technol.
Eng., vol. 57, no. 2, pp. 70-97, 2018

[2] V. H. Nguyen and J. J. Shim, "Green synthesis and characterization of carbon nanotubes/polyaniline nanocomposites," J. Spectrosc., vol. 2015, no. April, 2015.

[3] C. Dhand, M. Das, M. Datta, and B. D. Malhotra "Recent advances in polyaniline based biosensors," Biosens. Bioelectron., vol. 26, no. 6, pp. 2811-2821, 2011.

[4] A. A. Athawale and M. V. Kulkarni, "Polyaniline and its substituted derivatives as sensor for aliphatic alcohols," Sensors Actuators, B Chem., vol. 67, no. 1, pp. 173-177, 2000.

[5] J. Gao, J. M. Sansiñena, and H. L. Wang, "Chemical vapor driven polyaniline sensor/actuators," Synth. Met., vol. 135-136, pp. 809-810, 2003.

[6] Y. Lvov, R. Nohria, R. K. Khillan, Y. Su, R. Dikshit, and K. Varahramyan, "Humidity sensor based on ultrathin polyaniline film deposited using layer-by-layer nano-assembly," Sensors Actuators B Chem., vol. 114, no. 1, pp. 218-222, 2005.

[7] Z. L. Hua, J. L. Shi, L. X. Zhang, M. L. Ruan, and J. N. Yan, "Formation of nanosized $\mathrm{TiO} 2$ in mesoporous silica thin films," Adv. Mater., vol. 14, no. 11, pp. 830 833, Jun. 2002.

[8] A. Rothschild, Y. Komem, A. Levakov, N. Ashkenasy, and Y. Shapira, "Electronic and transport properties of reduced and oxidized nanocrystalline $\mathrm{TiO} 2$ films," Appl. Phys. Lett., vol. 82, no. 4, pp. 574-576, 2003.

[9] S. Stankovich et al., "Graphene-based composite materials," Nature, vol. 442, p. 282, 2006.

[10] J. Wu, W. Pisula, and K. Müllen, "Graphenes as Potential Material for Electronics," Chem. Rev., vol. 107, no. 3, pp. 718-747, 2007.

[11] Xuan Wang, * Linjie Zhi, and and Klaus Müllen*, "Transparent, Conductive Graphene Electrodes for DyeSensitized Solar Cells," Nano Lett., vol. 8, no. 1, pp. 323-327, 2008.

[12] M. D. Stoller, S. Park, Y. Zhu, J. An, and R. S. Ruoff, "Graphene-Based Ultracapacitors," Nano Lett., pp. 610, 2008.

[13] H. Wang, Q. Hao, X. Yang, L. Lu, and X. Wang, "Effect of graphene oxide on the properties of its composite with polyaniline," ACS Appl. Mater. Interfaces, vol. 2, no. 3, pp. 821-828, 2010.

[14] Q. Wu, Y. Xu, Z. Yao, A. Liu, and G. Shi, "Supercapacitors Based on Flexible Nanofiber, Graphene Polyaniline," ACS Nano, vol. 4, no. 4, pp. 1963-1970, 2010

[15] S. Srivastava, S. S. Sharma, S. Kumar, S. Agrawal, M. Singh, and Y. K. Vijay, "Characterization of gas sensing behavior of multi walled carbon nanotube polyaniline composite films," Int. J. Hydrogen Energy, vol. 34, no. 19, pp. 8444-8450, 2009.

[16] S. Srivastava, S. S. Sharma, S. Agrawal, S. Kumar, M. Singh, and Y. K. Vijay, "Study of chemiresistor type CNT doped polyaniline gas sensor," Synth. Met., vol. 160, no. 5-6, pp. 529-534, 2010.

[17] R. E. HummersJr, W.S.; Offeman, "Preparation of Graphitic Oxide 1339-1339.pdf," J. Am. Chem. Soc., vol. 80, pp. 1339-1339, 1958.

[18] A. E. Hed, "Structural and dielectric properties of polyaniline / $\mathrm{TiO} 2$ Nano-composites MUHAMMAD IRFAN1 ABDUL SHAKOOR," no. June, 2016. 